\title{
РОЛЬ НАУЧНО-ИССЛЕДОВАТЕЛЬСКОЙ РАБОТЫ СТУДЕНТОВ В ПОДГОТОВКЕ БУДУЩИХ СПЕЦИАЛИСТОВ
}

\section{THE ROLE OF STUDENTS' RESEARCH WORK IN TRAINING THE FUTURE SPECIALISTS}

O. Bolbat

E. Zakirova

O. Hekalo

Summary: The article is devoted to the topic dealing with study of the role of students' research work in a university, which is important for the formation of basic competencies in the process of training future competitive and highly qualified specialists. The article describes the practical experience of organizing and implementing students' research work being done by teachers of the Siberian State Transport University. The possibilities and features of the implementation of individual educational trajectories by students in the context of their participation in the project "Young Professionals (Increasing the Competitiveness of Professional Education)", which is part of the National Project "Education" are considered in the given article.

Keywords: students' research work, national project, competencies, professional communication.
Болбат Ольга Борисовна

К.n.н., дочент, ФГБОУ ВО «Сибирский государственный университет путей сообщения» (2. Новосибирск) olgab2203@gmail.com

Закирова Елена Сергеевна

Д.филол.н., профессор, ФГБОУВО «Московский государственный лингвистический университет (МГЛУ)»

zes.64@mail.ru

Хекало Ольга Юрьевна

К.т.н., дочент, ФГБОУ ВО «Сибирский государственный университет путей сообщения» (2. Новосибирск)

new_holga@mail.ru

Аннотация: Статья посвящена актуальной теме, связанной с изучением роли научно-исследовательской работы студентов (НИРС) в вузе, имеющей важное значение для формирования базовых компетенций в процессе подготовки будущих конкурентоспособных и высококвалифицированных специалистов. В статье описывается практический опыт организации и реализации НИРС преподавателями Сибирского государственного университета путей сообщения (СГУПС). В статье рассматриваются возможности и особенности реализации студентами индивидуальных образовательных траекторий в условиях их участия в проекте «Молодые профессионалы (повышение конкурентоспособности профессионального образования)», который является частью Национального проекта «0бразование».

Ключевые слова: научно-исследовательская работа, Национальный проект, компетенции, профессиональная коммуникация.

вузах вполне очевидна.

В настоящее время многими отечественными педагогами-практиками широко обсуждаются вопросы непрерывного образования [2]. Следует отметить, что потребность в самообразовании и саморазвитии будущих специалистов вызвана экономическими преобразованиями в нашей стране, в результате которых возникает необходимость в развитии конкурентоспособности личности.

Многие педагоги считают, что задачи современного непрерывного образования невозможно решить без повышения роли самостоятельной работы студентов. В учебных планах многих дисциплин значительно увеличилось количество часов для самостоятельной работы студентов, которое иногда превышает количество часов, отведенное на контактную работу с преподавателем. Правильно организованная самостоятельная работа мотивирует студентов на изучение учебного материала, вызывает интерес к научно-исследовательской работе, повышает эффективность образовательной деятельности, что, несомненно, является необходимым условием 
становления грамотного, инициативного, ответственного специалиста, готового к будущей профессиональной деятельности [3], [4], [5].

Одной из задач системы образования является формирование у студентов целеполагания на непрерывное обучение в течение всей жизни. Считаем, что если студенты в процессе обучения привыкли самостоятельно «добывать» знания, то и в своей будущей профессиональной деятельности они будут стремиться действовать аналогично. Как показывает практический опыт, развитие творческих и мыслительных способностей будущих специалистов возможна благодаря вовлечению студентов в различные проекты научно-исследовательской работы, которая определяется как компонент профессиональной подготовки.

Согласно основным образовательным программам, целью самостоятельной работы студентов, кроме получения необходимых знаний, развития умений, навыков и компетенций, является освоение научной методологии и формирование готовности к творческой и научной деятельности. Результаты педагогических наблюдений показывают, что самостоятельная работа студентов развивает ответственность, организованность, формирует творческий подход к решению нестандартных задач. К важнейшим задачам изучения любой учебной дисциплины относится организация самостоятельной работы, в процессе которой студент должен овладеть ее основными видами и формами, приобрести навыки ее реализации [1], [6].

В настоящее время необходимость в качественной профессиональной подготовке будущих высококвалифицированных конкурентоспособных специалистов [7], [8] находит свое отражение в образовательных стандартах нового поколения, главным образом, в современных требованиях к выпускнику вуза, который должен: обладать профессиональной грамотностью и компетентностью; идти в ногу со временем, постоянно повышая свою профессиональную квалификацию; быть конкурентоспособным, ответственным, способным на принятие самостоятельных решений поставленных задач [9], [10].

Считаем необходимым, начиная в первых дней обучения в вузе, привлекать студентов к научно-исследовательской деятельности, являющейся одним из актуальных направлений, целесообразность которой определяется государственными образовательными стандартами нового поколения. В качестве примера, подтверждающего факт включения научно-исследовательской деятельности, можно привести Федеральные государственные образовательные стандарты высшего образования для направлений подготовки: 23.05 .04 «Эксплуатация железных дорог»; 23.05 .06 «Строительство железных дорог, мостов и транспортных тоннелей» специализаций «Тоннели и метрополитены» и «Мосты»; 27.03.01 «Стандартизация и метрология»; 09.03.03 «Прикладная информатика». Как показывает педагогический опыт, вовлечение студентов в научно-исследовательскую деятельность способствует подготовке профессионально грамотных специалистов, обладающих набором необходимых компетенций, включая развитие способностей к проведению научно-исследовательской работы [5], [7].

В данной статье представлен опыт работы кафедры «Графика» СГУПС, имеющей особую специфику поскольку преподаватели работают со студентами всех факультетов. Проведение научно-технической конференции студентов и аспирантов «Наука и молодежь XXI века» является традиционным в СГУПС. В рамках данной конференции на кафедре «Графика» ежегодно работают две секции: «Графика вокруг нас» (включающая в себя работы по деловой и презентационной графике и формированию отчетной документации), и «Инженерная и компьютерная графика» (включающая работы студентов всех технических специальностей вуза). Следует отметить, что темы студенческих докладов всегда интересные и разносторонние. Приведем пример некоторых тем XIX научно-технической конференции студентов и аспирантов «Наука и молодежь XXI века» 2020 года: «Многогранники в архитектуре», «Кривая циклоида», «Использование компьютерной графики в дизайне одежды», «Анализ электронных учебных пособий», «Фотоны в образовании поверхностей», «Создание трехмерной модели вентиля к баллону с хлором», «История развития начертательной геометрии» и др. Кроме того, каждый год в весенний период в университете проводится традиционное мероприятие - студенческая конференция, посвященная Дням Науки, во время которой студенты представляют свои доклады в сопровождении презентаций, выступают перед жюри оргкомитета конференции. Студенты работают под руководством своего научного руководителя, который помогает им в представлении информации и подготовки доклада. Выступая на научных конференциях, студенты приобретают бесценный опыт публичной защиты своего проекта, имеющий важное значение для становления и развития лидерских качеств, необходимых для будущих руководителей. Итогом проведения данной конференции является публикация лучших докладов в материалах конференции и вручение ценных призов, что, несомненно, мотивирует и является стимулом для дальнейшей научной деятельности студентов.

Традиционно преподаватели кафедры «Графика» в период проведения конференции, посвященной Дням Науки, организовывают несколько предметных олимпиад, конкурсы, выставки и т.д. [6]. Итак, каждый год в вузе проводятся олимпиады по начертательной геометрии, трехмерному моделированию в SolidWorks и КОМПАС, конкурс «Лучшие графические работы». Считаем, что 
НИРС под руководством преподавателя направлена на углубленное изучение теоретических вопросов, студенты вовлекаются в поисково-познавательную деятельность, ориентированную на поиск и отбор информации. В связи с этим, темы конференций для студентов первого курса, в основном, имеют реферативный характер. Поскольку дисциплины кафедры «Графика» преподаются студентам первого и второго курсов, преподаватели имеют возможность привлекать студентов к научной деятельности, начиная с первого года обучения.

В связи с этим направлением работы, годовой план мероприятий по НИРС кафедры «Графика» состоит из двух разделов: 1) «Олимпиады и конкурсы» и 2) «Конференции и выставки». В последние годы отчет по первому разделу «Олимпиады» включает в себя участие студентов: во Всероссийской Олимпиаде по начертательной геометрии, инженерной и компьютерной графике, проводимой на базе Российского технологического университета МИРЭА (г. Москва); в Межвузовской олимпиаде по инженерной графике и Всероссийской олимпиаде по компьютерной графике, которые проводятся на базе Новосибирского государственного технического университета НГТУ (г. Новосибирск) и др. Кроме того, преподаватели кафедры организовывают и проводят на базе университета (СГУПС) Всероссийскую интернет-олимпиаду по дисциплинам графического цикла (г. Новосибирск).

В рамках мероприятий раздела «Конкурсы» в СГУПС ежегодно проводится конкурс на лучшую научную работу студентов, организация и проведение которого также осуществляется преподавателями кафедры «Графика». В текущем году впервые планируется организация и проведение Межвузовской студенческой научно-практической конференции «Инженерная и компьютерная графика: вчера, сегодня, завтра», которое следует отнести к мероприятиям, развивающим перспективную деятельность кафедры. Следует отметить, что ежегодно студенты под руководством ППС кафедры готовятся и принимают участие в Региональном конкурсе по начертательной геометрии и инженерной графике, проводимом в Новосибирском государственном архитектурностроительном университете (НГАСУ) (г. Новосибирск).

Особое положение в деятельности кафедры «Графика» занимают студенты экономических направлений: для их подготовки введены новые дисциплины [8]; их активность в НИРС оценивается также высоко, как и участие студентов инженерных направлений. Так, в ноябре 2020 г. студенты инженерно-экономического факультета и факультета «Мировая экономика и право» подготовили проекты и приняли участие во Всероссийском конкурсе молодежных проектов стратегии социально-экономического развития «РОССИЯ-2035». Данный конкурс организован при информационной поддержке Совета
Федерации Федерального Собрания РФ. Данный конкурс проводится на всей территории нашей страны в два этапа (заочный и очный). Основными задачами его проведения является повышение гражданской активности и формирование представления молодежи о собственной роли в социально-экономическом развитии страны; выявление, поддержка и развитие талантливой молодежи. Трое студентов, подготовленных преподавателями кафедры «Графика», из десяти представителей вузов Новосибирской области, успешно прошли заочный этап и приглашены в Москву для очного участия в конкурсе. Кроме вышеперечисленного, к вузовским мероприятиям нужно добавить проведение конкурса студенческих грантов, ставшего ежегодным. Данный конкурс проводится по двум направлениям: техническому и гуманитарному.

Важнейшим подходом к научно-исследовательской деятельности кафедры в рамках разработки исследовательских проектов, а также в процессе подготовки к научным конференциям следует считать работу преподавателей со студентами, направленную на формирование как профессиональных, так и коммуникативных компетенций [11], [12]. Безусловно, становление специалиста невозможно без освоения как специальных знаний, так и овладения коммуникативными навыками, реализация которых, имеет взаимосвязанный и взаимообусловленный характер. Особенности профессиональной и деловой коммуникации имеют определенные отличия в зависимости от сферы, в которой осуществляется общение специалистов [13], [14].

Как показывает многолетний опыт, эффективность развития профессиональной коммуникативной компетенции базируется на освоении студентами специальных, межнаучных, общенаучных терминов, понятий и их определений. Использование в НИРС достижений в области теории и практики языка для специальных целей, в основном, разработанные лингвистические методы позволяют развивать у студентов способности самостоятельно осваивать понятийный аппарат изучаемой специальности (направления подготовки), а также терминологию, используемую в выпускных квалификационных работах, диссертациях и др. [15]. Студентами изучаются особенности функционирования терминологии с учетом развития профессионального мышления и практической деятельности и затем осознанно используются в их устной и письменной речи, характеризуя степень сформированности профессиональной языковой личности и уровень овладения специальными знаниями. Считаем, что данный подход к научно-исследовательской деятельности студентов усиливает научную новизну, практическую значимость проводимой в данном направлении работы кафедры «Графика». Таким образом, организация научно-исследовательской работы студентов в СГУПС создает благоприятные условия для 
развития и формирования профессионально-значимых качеств будущих специалистов. Научно-исследовательская работа способствует развитию у студентов способностей к постоянному самообразованию, принятию самостоятельных решений, поиску возможностей для применения своих знаний в решении различных практических и творческих задач, навыков профессиональной коммуникации [6], [9], [16].

Считаем, что мотивация к научно-исследовательской деятельности усиливается благодаря как моральным (торжественное вручение грамот и дипломов), так и материальным поощрениям (ценные подарки и денежная премия) студентов. Кроме того, студентам, имеющим особые достижения в НИРС в зависимости от суммы набранных в течение учебного года баллов, назначается повышенная стипендия, размер которой определяется также уровнем мероприятий (выступление на конференциях, участие в конкурсах и олимпиадах, публикация статей), в которых студент участвует. Так, например, участие во всероссийской олимпиаде приносит больше баллов, чем в городской или региональной. На наш взгляд, участие в НИРС способствует формированию профессиональных качеств и компетенций студентов, отвечающих требованиям государственного заказа и имеющих важное значение для будущей деятельности [3], [16], [17].
В заключении считаем необходимым отметить, что требуется дальнейшая активизация научно-исследовательской работы студентов, которая представляется возможной благодаря: привлечению большего количества участников конференций, семинаров, конкурсов; усилению студенческой публикационной активности под руководством преподавателей; освоению специальной терминологии и языка для специальных целей, обслуживающих профессиональную коммуникацию и др. Таким образом, в ходе научно-исследовательской деятельности отмечается формирование профессиональных и коммуникативных компетенций, способствующих развитию интеллектуального потенциала и творческого мышления студентов, приобретению опыта в отстаивании своей точки зрения во время публичных выступлений, становлению профессиональной культуры и особых качеств, важных и необходимых будущим специалистам. Считаем, что многоплановая и целенаправленная деятельность профессорско-преподавательского состава кафедры «Графика», а также других кафедр СгуПС [17], обеспечивает решение задач, поставленных в рамках реализации проекта «Молодые профессионалы (повышение конкурентоспособности профессионального образования)» [18], входящего в Национальный проект «Образование» [19].

\section{ЛИТЕРАТУРА}

1. Официальный сайт Сибирского государственного университета путей сообщения [Электронный ресурс] URL: http://www.stu.ru/about/index.php?page=2373 (Дата обращения 17.11.2020).

2. Кривич, С.В. Характеристика численности студентов в российских вузах / С.В. Кривич, 0.Ю. Хекало // В сборнике: Социальная работа в современном мире: взаимодействие науки, образования и практики: проблемы детей и молодежи в контексте социально-гуманитарных исследований. Сборник научных статей XI Международной научно-практической конференции, посвященной Десятилетию детства в России. Белгород, 2019. С. 182-189.

3. Речкин, М.К. Профессиональная востребованность на рынке труда и выбор молодежи /М.К. Речкин, 0.Ю. Хекало В сборнике: Молодежь в меняющемся мире: траектории самоопределения в глобальной современности. Материалы ХІ Всероссийской научно-практической конференции. Научный редактор Л.А Беляева, отв. редактор Н.А. Симбирцева. 2019. С. 128-134.

4. Болбат, 0.Б. Современное графическое образование в техническом вузе (на примере обзора графических работ студентов СГУПС) / 0.Б. Болбат // Современный взгляд на будущее науки. Сборник статей Международной научно-практической конференции. 2015. С. 127-132.

5. Болбат, О.Б. Проблемы высшего технического образования в области дисциплин графического цикла / О.Б. Болбат, Н.К. Шабалина // Проблемы современного педагогического образования. 2018. № 61-2. С. 87-91.

6. Астахова, Т.А. Активизация самостоятельной работы студентов в курсе графических дисциплин посредством участия в олимпиадах и конкурсах / Т.А. Астахова // Инновационные технологии в инженерной графике: проблемы и перспективы / сборник трудов Международной научно-практической конференции. Новосибирский государственный архитектурно-строительный университет (Сибстрин), Брестский государственный технический университет. 2018. С. 29-32.

7. Андрюшина, Т.В. Тенденции и перспективы общественного спроса в области высшего образования / Т.В. Андрюшина, 0.Ю. Хекало // В сборнике: Актуальные проблемы модернизации высшей школы: резервы отечественной высшей школы в совершенствовании профессиональной подготовки специалистов. Материалы XXXI Всероссийской научно-методической конференции с международным участием. 2020. С. $22-25$.

8. Болбат, 0.Б. Опыт обучения студентов вуза формированию отчетов и созданию презентаций / 0.Б. Болбат, Е.С. Закирова, 0.Ю. Хекало // Современная наука: актуальные проблемы теории и практики. Серия: Гуманитарные науки. - 2020. - № 4-2. - C. 64-69. - DOI 10.37882/2223-2982.2020.04-2.08.

9. Петухова А.В. Компьютерное проектирование: опыт организации непрерывной системы обучения графическим дисциплинам / А.В. Петухова, 0.Б. Болбат // Актуальные проблемы современного образования: опыт и инновации / материалы научно-практической конференции (заочной) с международным участием. Ответственный редактор А.Ю. Нагорнова. 2014. С. 440-446.

10. Чупрова, Л.В. Активизация научно-исследовательской деятельности студентов в условиях реализации ФГОС ВПо / О.В. Ершова, Э.Р. Муллина, 
0.А. Мишурина // Фундаментальные исследования. - 2015. - № 2-19. - С. 4319-4323 [Электронный ресурс] URL: http://fundamental-research.ru/ru/ article/view?id=37951 (дата обращения: 17.03.2020).

11. Закирова Е.С., Карпова Т.А. Роль самостоятельной работы студентов технического вуза в процессе изучения иностранного языка для специальных целей. - Известия МГТУ «МАМИ». Вып. 2(14) 2012, т. 3. М.: МГТУ «МАМИ», 2012. С. 392-398

12. Закирова Е.С., Карпова Т.А. Организация самостоятельной работы студентов технического вуза в контексте компетентностного подхода в образовании. Автомобиле- и тракторостроение в России: приоритеты развития и подготовка кадров: материалы 77-й Международной научно-технической конференции Ассоциации автомобильных инженеров (ААИ). М.: МГТУ «МАМИ», 2012. С. 183-191

13. Закирова Е.С., Циленко Л.П., Циленко К.C. Global Scientific Collaboration: Suggestions on Bridging Gaps. - В сборнике: преподавание английского языка в профессиональном контексте: соединяем культуры через границы. Матер. 4-й Междунар. науч.-практ. конф.. Министерство науки и высшего образования Российской Федерации, Федеральное государственное бюджетное образовательное учреждение высшего образования "Тамбовский государственный технический университет". 2019. С. 44-48.

14. Закирова Е.С., Циленко Л.П., Шиповская А.А., Щербо П.А. Metacognitive Based Collaboration in Scientific Research. - В сборнике: Материалы Всероссийской научно-практической конференции. Редколлегия: Е.И. Абрамова (отв. ред.) [и др.]. 2020. С. 276-282.

15. Основы теории языка для специальных целей: Учебник / Э.А. Сорокина, Е.С. Закирова. - М.: ИТК «Дашков и К», 2014. 152 с.

16. Абрамов А.Д., Манаков А.Л., Маслов Н.А. Инновационные разработки студенческого научного объединения СГУПС - производству. Железнодорожный транспорт. 2020. № 3. С. 66-70.

17. Гербер А.Р. Научная школа путейцев. Вестник Сибирского государственного университета путей сообщения. 2007. № 16. С. 77-80.

18. Новосибирская открытая образовательная сеть [Электронный ресурc]. URL: https://www.edu54.ru/projects/npe/182683/ (дата 0бращения: 17.11.2020).

19. Официальный сайт Министерства просвещения России [Электронный ресурс]. URL https://edu.gov.ru/national-project/ (дата 0бращения: 17.11.2020).

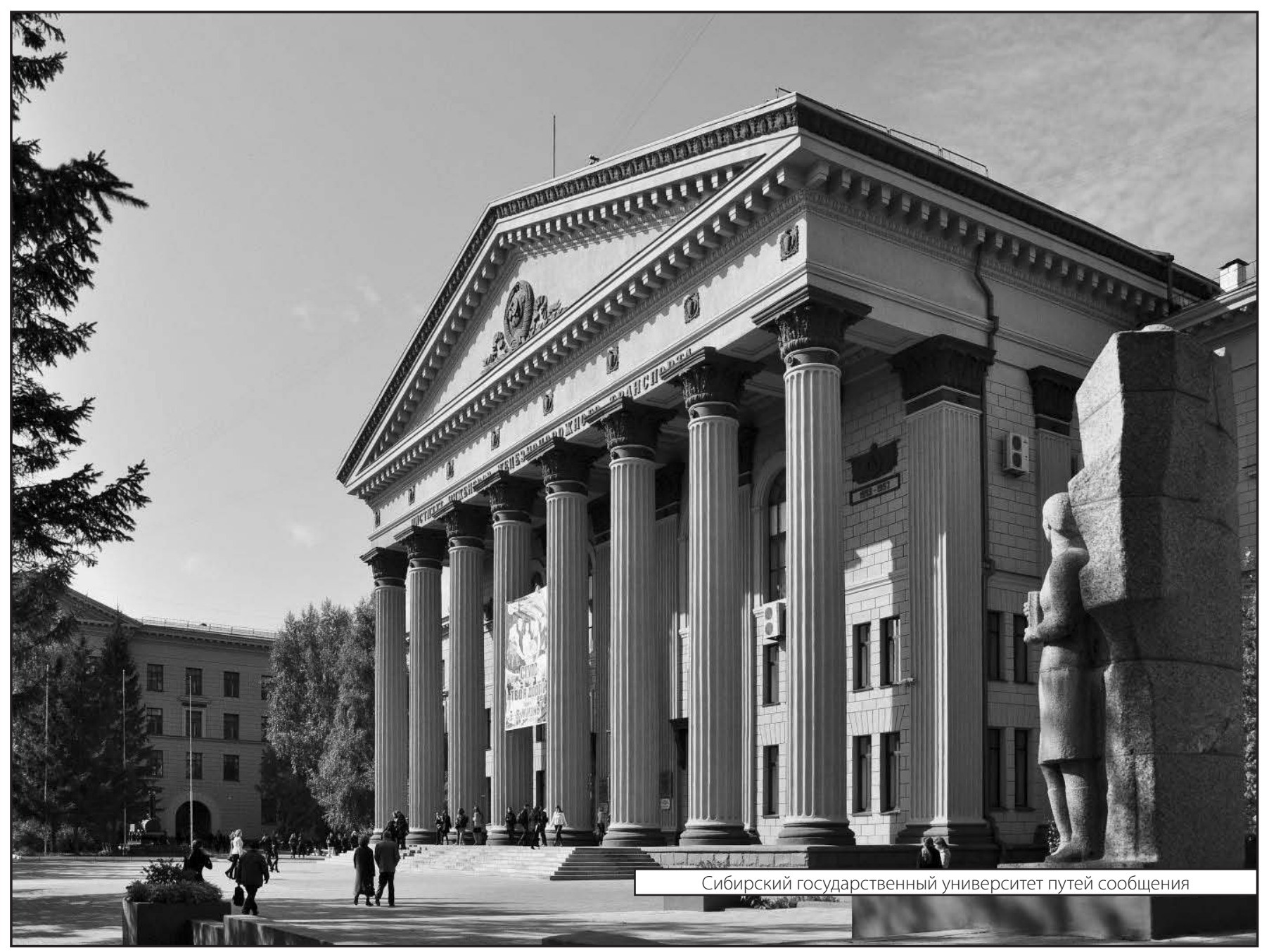

